\title{
Description of environmental determinants of quality of life in children with intellectual disability in Japan using the Delphi technique
}

\author{
Luyinga Kalay $\cdot$ Saeko Fujimori $\cdot$ Hanako Suzuki · \\ Keiko Minamoto $\cdot$ Kimiyo Ueda $\cdot$ Chang-Nian Wei · \\ Akemi Tomoda $\cdot$ Koichi Harada $\cdot$ Atsushi Ueda
}

Received: 23 April 2009/Accepted: 1 September 2009/Published online: 7 October 2009

(C) The Japanese Society for Hygiene 2009

\begin{abstract}
Objectives The present study aimed to define the framework of an environment conducive to the well-being of children with intellectually disability (CID).

Methods A questionnaire composed of 31 items was developed through literature review. Then a 2-round Delphi survey was conducted with 3 different panels: health professionals (HPs), parents of CID, and teachers. The participants were asked to rate each item, select and rank the 10 most important items, and suggest additional ones. Results A total of 71 participants responded to the first round: 24 HPs, 22 parents, and 25 teachers. In the second round the overall response rate was $83 \%$. At the end of the exercise, 12 items reached global consensus, i.e., in all groups. Only 5 items were ranked as most important by all
\end{abstract}

L. Kalay $(\bowtie) \cdot$ S. Fujimori $\cdot$ K. Minamoto .

C.-N. Wei · A. Ueda

Department of Preventive and Environmental Medicine,

Graduate School of Medical and Pharmaceutical Sciences,

Kumamoto University, 1-1-1 Honjo,

Kumamoto 860-8556, Japan

e-mail: anifakalay@yahoo.fr

H. Suzuki · A. Tomoda

Department of Child Development, Graduate School of Medical and Pharmaceutical Sciences, Kumamoto University,

1-1-1 Honjo, Kumamoto 860-8556, Japan

K. Ueda

Department of Community Health Nursing, School of Health

Sciences, Kumamoto University, 4-24-1 Kuhonji,

Kumamoto 862-0976, Japan

K. Harada

Department of Microbiology and Environmental Chemistry,

School of Health Sciences, Kumamoto University,

4-24-1 Kuhonji, Kumamoto 862-0976, Japan groups: attitudes of family members at home; attitudes of HPs and teachers; support from family members at home; support at school (classmates and teachers); and government policies. Nevertheless, the panelists' views diverged on the remaining items. Several additional elements were suggested.

Conclusions The views of HPs, teachers, and parents are complementary for the improvement of quality of life (QOL) of CID. The present findings will be used as a basis for the development of an instrument to assess the living environment of CID.

Keywords Quality of life - Intellectual disability . Child · Delphi technique $\cdot$ Environment

\section{Introduction}

The current stance of the World Health Organization (WHO) about disability-the biopsychosocial modelemphasizes the role of both environment and personal factors to determine participation of people with disablity in society. The International Classification of Disability and Functioning (ICF) operationalizes this complex relationship [1]. On the other hand, another concept-quality of life (QOL) -is also related to environment and individual factors, as stated in the WHO definition: QOL is an individual's perception of his/her position in life in the context of the culture and value systems in which he/she lives, and in relation to his/her goals, expectations, standards, and concerns. It is a broad-ranging concept, incorporating in a complex way the person's physical health, psychological state, level of independence, social relationships, and their relationship to salient features of their environment [2]. 
Environment simultaneously affects not only participation but also QOL in the general population $[3,4]$ and more particularly in people with disability $[5,6]$. Indeed, environmental modifications may often be the only feasible intervention to improve QOL and increase participation of people with disability since most disabilities are incurable [7, 8]. However, few studies have described the link between these 3 concepts (participation, QOL, and environment) for people with disability [9-11]. In order to plan and monitor the environmental programs required easy-to-use and reliable instruments are necessary.

To date, several questionnaires have been developed to assess the environment of people with disability [12]. All have been initially developed either in Europe or America, posing the question of cross-cultural adequacy in other environmental contexts. Moreover, most of those instruments address adults [12]. Obviously, these measures are not adapted to the child's environment. Nevertheless, children and adults with disability face the same challenges in their daily life [13, 14].

Little research has been conducted on the environment of children with disability in an exhaustive manner, i.e., on the 3 aspects of physical environment, attitudes and support, and social environment [11]. Often, only selected aspects of the environment are explored [15]. Emphasis is frequently placed on physically challenged children, whereas their peers with intellectual disability are rarely addressed. Although intellectual disability is an invisible disability, children with intellectual disability do face the same challenges as their peers with physical disability.

Intellectual disability (ID) is the commonest developmental disability. Currently $1-3 \%$ of the world population lives with ID [16]. In Japan 329000 people live with ID and 93600 of them are children (0-17 years old) [17]. ID, as other disabilities, is a condition expected to increase with the extended survival of children with disability secondary to the advancement of medical science. In Japan, studies pertaining to the environment related to people with ID are scarce. They report mainly on attitudes towards ID $[18,19]$ or matters related to people with ID such as social services utilization [20]. Obviously information about the needs of children with intellectual disability is lacking. Consequently, it is necessary to fill this gap.

In this study, we aimed to define the framework of an environment conducive to the well-being of children with intellectual disability. This is a fundamental step towards the development of an instrument to assess the environment of these children.

The present article reports the Delphi survey that was conducted to achieve this aim.

\section{Materials and methods}

\section{Delphi technique}

Since it was first published in 1964 [23], the Delphi technique has been used in various areas of health research [24-27].

It is a process involving a panel of experts replying to a series of questionnaires followed by feedback through 2 or more successive rounds [21]. Its objective is to obtain a consensus among the panelists in addressing a specific problem. It is recommended when investigating a problem for which information is not completely available. It has 3 main characteristics: anonymity, controlled feedback, and statistical group response [21]. Anonymity is ensured, because the participants' identities are hidden from each other by using questionnaires. Controlled feedback is realized through successive rounds where the questionnaire is returned to the participants with a summary of answers gathered in previous rounds. Respondents have the opportunity to change their opinion if they wish. Statistical group response allows everyone's opinion to be represented in the final response, thus expressing the degree of consensus in the group. In this study, a 2-round Delphi survey was conducted.

\section{Subjects}

It has been proposed that, with a homogenous group of experts, acceptable results can be achieved with small panels of 10-15 individuals [21]. A homogeneous group is a group of experts from the same general discipline area [22].

In this study, we involved 3 different panels, made up of teachers, parents, and health professionals (HPs), respectively. Homogeneity between groups was assured by the fact that all participants fulfilled the selection criterion of being committed to disabled children's well-being either in daily life (parents), in their profession (teachers and HPs), or through an association. In addition, homogeneity within the groups was assured by the fact that participants within a group had a similar relationship with children with intellectual disability, either familial (parents), health-related (HPs), or educational (teachers).

Teachers and parents were contacted through primary and junior high schools or associations devoted to children with disability in one prefecture in Kyushu Island, Japan. Health professionals were recruited at 1 university hospital and 2 centers for children with disability on Kyushu Island, Japan. The investigators personally explained the process of the study to the representative of associations and head of hospitals/departments. Then envelopes containing questionnaires and return envelopes were given to them. 
They were asked to distribute them to the members of the associations and hospitals staff. Answers were to be either sent by mail or collected at the association or hospitals.

\section{Ethics}

Before starting the survey, we obtained authorization from the ethical committee of our university. Information about the study was provided to all participants, and informed consent was obtained.

\section{Procedure}

\section{Literature review}

A literature search of questionnaires assessing environment as applicable to disabled people was conducted. The following databases were searched: Pubmed, Scopus, ISI web of knowledge, and Ovid. Instruments that assessed environment in an exhaustive manner, i.e., in the 3 domains of physical environment, attitudes and support, and social environment, were selected [11, 28-30]. Then a content analysis was performed to extract the themes included in the selected instruments. Content analysis is a method widely used in qualitative research [31-33]. It consists of "organizing written, audio or visual information into categories related to the central questions of the study" [34]. Finally, a panel constituted of experts in preventive and environmental medicine and child development was convened to debate the contents of the Delphi survey based on the extracted themes. After discussions and refinement a final pool of 31 questions was developed. They were distributed as follows: 9 questions pertaining to physical environment, 12 questions pertaining to attitudes and support, and 10 questions pertaining to social environment.

\section{First round}

The participants were sent a questionnaire of 31 questions divided into 3 categories. They were asked to determine their perception of the importance of each item for the well-being of a child with intellectual disability. A 5-point Likert scale ranging from 1 (not important at all) to 5 (very important) was used. Then they had to state the reason for their choice. At the end of each category, an open-ended question asked panelists to suggest additional items.

\section{Second round}

The panelists were sent feedback from the first round in which they were provided with the answer they made in the first round and informed of the comments that were expressed in their respective group along with the same questionnaire. They were asked to reply to the questionnaire in the same way as in the first round but were informed that they could change their answers if they wished. Moreover, they were asked to select and rank in order the 10 elements that they judged most important for children with intellectual disability.

Data analysis

For the Likert-scale questions, the percentage realized in each scale, i.e., from 1 to 5 , was computed. In the second round, consensus was considered as met when an item was scored 4 (important) or 5 (very important) by at least $75 \%$ of the participants within a group. The consensus threshold of $75 \%$ is the equivalent of the views of participants in the fourth quartile. The consensual items were retained in the framework of the factors that influence QOL of children with intellectual disability.

In addition, in the second round the 10 items that were selected as most important by each participant were analyzed by assigning points. This procedure was performed to reveal the items that participants judged as priorities for children with ID. An item ranked as the most important was assigned 10 points and an item ranked as the least important was assigned 1 point. Then the assigned points were summed to obtain the total score.

Furthermore, participants' suggestions were translated into English and then analyzed by content analysis. Data extraction was carried out manually. The emerging themes were assigned to 1 of the 3 domains of the environment: physical environment, attitudes and support, and social environment.

Eventually, Spearman's rho was performed to reveal the relationship between rounds 1 and 2 and to assess whether a supplementary (third) round was required.

\section{Results}

Delphi participants

\section{First round}

Seventy-one participants including 24 HPs, 25 teachers, and 22 parents replied to the first round. Participants' detailed demographic features are presented in Table 1.

Ten parents reported that their child had another disability combined with ID: 5 had a mental illness and 5 presented physical disorders. One child had an association of the 3 disabilities. The intellectual disability levels ranged from mild to severe. 
Table 1 Participants' demographic features

\begin{tabular}{|c|c|c|c|c|c|c|}
\hline & \multicolumn{2}{|l|}{ HPs } & \multicolumn{2}{|l|}{ Teachers } & \multicolumn{2}{|l|}{ Parents } \\
\hline & $\begin{array}{l}\text { Both rounds } \\
(n=22)\end{array}$ & $\begin{array}{l}\text { First round only } \\
(n=2)\end{array}$ & $\begin{array}{l}\text { Both rounds } \\
(n=18)\end{array}$ & $\begin{array}{l}\text { First round } \\
\text { only }(n=7)\end{array}$ & $\begin{array}{l}\text { Both rounds } \\
(n=19)\end{array}$ & $\begin{array}{l}\text { First round } \\
\text { only }(n=3)\end{array}$ \\
\hline Characteristics & No. (\%) & No. $(\%)$ & No. (\%) & No. (\%) & No. (\%) & No. $(\%)$ \\
\hline \multicolumn{7}{|l|}{ Age (years) } \\
\hline $20-29$ & 0 & $1(50.0)$ & 0 & 0 & $1(5.3)$ & 0 \\
\hline $30-39$ & 4 (18.2) & 0 & $2(11.1)$ & $1(14.3)$ & $5(26.3)$ & 0 \\
\hline $40-49$ & $12(54.5)$ & $1(50.0)$ & $8(44.4)$ & $2(28.6)$ & $11(57.9)$ & $2(66.7)$ \\
\hline $50-59$ & $6(27.3)$ & 0 & $8(44.4)$ & $2(28.6)$ & $2(10.5)$ & 0 \\
\hline $60-69$ & 0 & 0 & 0 & $1(14.3)$ & 0 & 0 \\
\hline Missing & 0 & 0 & $2(11.1)$ & $1(14.3)$ & 0 & $1(33.3)$ \\
\hline \multicolumn{7}{|l|}{ Sex } \\
\hline Male & $7(31.8)$ & $1(50.0)$ & $7(38.9)$ & $4(57.1)$ & 0 & $1(33.3)$ \\
\hline Female & $15(68.2)$ & $1(50.0)$ & $11(61.1)$ & $3(42.9)$ & $19(100.0)$ & $1(33.3)$ \\
\hline Missing & 0 & 0 & 0 & 0 & 0 & $1(33.3)$ \\
\hline \multicolumn{7}{|l|}{ Specialty } \\
\hline Pediatrics & $11(50.0)$ & $1(50.0)$ & - & - & - & - \\
\hline Child development & $5(22.7)$ & 0 & - & - & - & - \\
\hline Psychology & $3(13.6)$ & 0 & - & - & - & - \\
\hline Speech therapy & $1(4.5)$ & $1(50.0)$ & - & - & - & - \\
\hline Helper & $1(4.5)$ & 0 & - & - & - & - \\
\hline Physiotherapy & $1(4.5)$ & 0 & - & - & - & - \\
\hline \multicolumn{7}{|l|}{ School type } \\
\hline Mainstream & - & - & $3(16.7)$ & 0 & - & - \\
\hline Special school & - & - & $3(16.7)$ & $2(28.6)$ & - & - \\
\hline Special class & - & - & $10(55.6)$ & $4(57.1)$ & - & - \\
\hline Tsukyu $^{\mathrm{a}}$ & - & - & $2(11.1)$ & 0 & - & - \\
\hline Missing & - & - & 0 & $1(0.1)$ & - & - \\
\hline \multicolumn{7}{|l|}{ Child age (years) } \\
\hline $5-9$ & - & - & - & - & $6(31.6)$ & $1(33.3)$ \\
\hline $10-14$ & - & - & - & - & $4(21.1)$ & $1(33.3)$ \\
\hline $15-19$ & - & - & - & - & $8(42.2)$ & 0 \\
\hline$>19$ & - & - & - & - & $1(5.3)$ & 0 \\
\hline Missing & - & - & - & - & 0 & $1(33.3)$ \\
\hline \multicolumn{7}{|l|}{ Child sex } \\
\hline Female & - & - & - & - & 13 (68.4) & $1(33.3)$ \\
\hline Male & - & - & - & - & $6(31.6)$ & $1(33.3)$ \\
\hline Missing & - & - & - & - & 0 & $1(33.3)$ \\
\hline
\end{tabular}

a Tsukyu: resource room (room set up in a public school to provide support to children with disability)

\section{Second round}

Of the 71 questionnaires sent, 59 were returned (overall response rate $84.5 \%)$. Thus, 22 HPs (91.7\%), 19 parents $(86.4 \%)$, and 18 teachers $(72.0 \%)$ participated in the second round. Two parents could not be contacted since they had not provided contact details in the previous questionnaire. Reasons for nonparticipation of the other respondents are not known, although some reported lack of time.

According to the demographics and the items chosen, we estimated that the participants who took part in both rounds $(n=59)$ would not be influenced by the participants who dropped out $(n=12)$. Therefore, we used the 
Table 2 Consensus per group, round 1 and 2: physical environment

\begin{tabular}{|c|c|c|c|c|c|c|}
\hline \multirow[t]{2}{*}{ Physical environment questions } & \multicolumn{2}{|l|}{ HPs } & \multicolumn{2}{|c|}{ Teachers } & \multicolumn{2}{|l|}{ Parents } \\
\hline & R1 (\%) & $\mathrm{R} 2(\%)$ & R1 (\%) & $\mathrm{R} 2(\%)$ & $\mathrm{R} 1(\%)$ & $\mathrm{R} 2(\%)$ \\
\hline Neighborhood features (Q6) & 57.1 & 78.9 & 50 & 77.8 & 36.8 & 73.7 \\
\hline Assistive devices (Q8) & 61.9 & 75 & 77.8 & 88.2 & 63.2 & 73.7 \\
\hline Daily life utilities (Q9) & 61.9 & 85 & 66.7 & 82.4 & 66.7 & 64.7 \\
\hline Home type (Q1) & 57.1 & 71.4 & 35.3 & 37.5 & 57.9 & 63.2 \\
\hline Home design (Q2) & 57.1 & 76.2 & 27.8 & 18.8 & 52.6 & 52.6 \\
\hline Parks (Q3) & 61.9 & 61.9 & 66.7 & 72.2 & 42.1 & 42.1 \\
\hline Air quality (Q5) & 60 & 63.2 & 44.4 & 47.1 & 36.8 & 36.8 \\
\hline Vegetation (Q7) & 52.4 & 50 & 55.6 & 52.9 & 31.6 & 31.6 \\
\hline Natural environment (Q4) & 47.6 & 47.6 & 38.9 & 47.2 & 26.3 & 26.3 \\
\hline
\end{tabular}

Table 3 Consensus per group, round 1 and 2: attitudes and support

\begin{tabular}{|c|c|c|c|c|c|c|}
\hline \multirow[t]{2}{*}{ Attitudes and support questions } & \multicolumn{2}{|l|}{ HPs } & \multicolumn{2}{|l|}{ Teachers } & \multicolumn{2}{|l|}{ Parents } \\
\hline & $\mathrm{R} 1(\%)$ & $\mathrm{R} 2(\%)$ & $\mathrm{R} 1(\%)$ & $\mathrm{R} 2(\%)$ & $\mathrm{R} 1(\%)$ & $\mathrm{R} 2(\%)$ \\
\hline Attitudes of family at home (Q10) & 90.5 & 100 & 88.9 & 100 & 100 & 100 \\
\hline Attitudes of teachers and HPs (Q12) & 95.2 & 100 & 88.9 & 100 & 100 & 100 \\
\hline Support at school (Q17) & 61.9 & 76.2 & 83.3 & 100 & 94.7 & 100 \\
\hline Support from family members at home (Q15) & 71.4 & 85 & 72.2 & 94.4 & 94.7 & 94.7 \\
\hline Listen to parents' opinion (Q19) & 85.7 & 100 & 83.3 & 100 & 94.7 & 94.4 \\
\hline Attitudes of classmates and other age-mates (Q13) & 71.4 & 81 & 77.8 & 94.4 & 78.9 & 89.5 \\
\hline Attitudes of wider family (Q11) & 61.9 & 66.7 & 88.9 & 100 & 84.2 & 88.9 \\
\hline Support in the community (Q18) & 52.4 & 52.4 & 55.6 & 72.2 & 55.6 & 77.8 \\
\hline Support from wider family (Q16) & 47.6 & 52.4 & 61.1 & 82.4 & 68.4 & 73.7 \\
\hline Attitudes of people in public (Q14) & 61.9 & 76.2 & 66.7 & 72.2 & 57.9 & 63.2 \\
\hline Temporary child care by family and friends (Q20) & 45 & 50 & 56.3 & 70.6 & 44.4 & 36.8 \\
\hline Support from animals (pets) (Q21) & 42.9 & 35 & 27.8 & 33.3 & 29.4 & 27.8 \\
\hline
\end{tabular}

ratings of the second-round participants to select the consensus items.

\section{Consensus within groups}

The consensus level observed within groups at the end of the second round is reported below. Detailed results for each item during the first and second round are showed in Tables 2, 3, and 4 .

\section{HPs group}

Of the 31 items, 18 met the consensus criterion: 4 from the physical environment domain, 7 from the attitudes and support domain, and the remaining 7 from the social environment domain.

Six items reached the highest consensus level (100\%). Three belonged to the attitudes and support domain: attitudes of family at home, attitudes of teachers and health professionals, and listening to parents' opinions. The other three belonged to the social environment domain: government policies, programs and services in the community, and school type.

The item that reached the lowest consensus level belonged to the social environment domain: leisure facilities in the community (30\%).

\section{Teachers group}

Seventeen items met the consensus criterion: 3 from the physical environment domain, 8 from the attitudes and support domain, and 6 from the social environment domain.

Eight items reached the highest consensus level (100\%). Five belonged to the attitudes and support domain: attitudes of family at home, attitudes of teachers and health professionals, support at school, listening to parents' opinion, and attitudes of wider family. The three others belonged to the social environment domain: government 
Table 4 Consensus per group, round 1 and 2: social environment

\begin{tabular}{|c|c|c|c|c|c|c|}
\hline \multirow[t]{2}{*}{ Social environment questions } & \multicolumn{2}{|l|}{ HPs } & \multicolumn{2}{|c|}{ Teachers } & \multicolumn{2}{|l|}{ Parents } \\
\hline & $\mathrm{R} 1(\%)$ & $\mathrm{R} 2(\%)$ & $\mathrm{R} 1(\%)$ & $\mathrm{R} 2(\%)$ & $\mathrm{R} 1(\%)$ & $\mathrm{R} 2(\%)$ \\
\hline Government policies (Q24) & 85.7 & 100 & 83.3 & 100 & 100 & 100 \\
\hline Cooperation among social services (Q25) & 85.7 & 95.2 & 88.9 & 100 & 100 & 100 \\
\hline Programs and services in the community (Q31) & 81 & 100 & 88.9 & 100 & 94.7 & 100 \\
\hline School type (Q26) & 85 & 100 & 64.7 & 83.3 & 89.5 & 88.2 \\
\hline Respite services (Q30) & 76.2 & 90.5 & 55.6 & 72.2 & 73.7 & 83.3 \\
\hline Parents' support group (Q28) & 81 & 95.2 & 77.8 & 94.1 & 68.4 & 77.8 \\
\hline Parents' counseling services (Q29) & 71.4 & 95.2 & 77.8 & 88.2 & 78.9 & 77.8 \\
\hline Leisure facilities in the community (Q22) & 28.6 & 30 & 50 & 47.1 & 47.4 & 44.4 \\
\hline Cultural services in the community (Q23) & 38.1 & 35 & 66.7 & 70.6 & 42.1 & 44.4 \\
\hline Home-helper (Q27) & 55 & 61.9 & 33.3 & 47.1 & 52.6 & 44.4 \\
\hline
\end{tabular}

policies, cooperation among social services, and programs and services in the community.

The item that reached the lowest consensus level belonged to the physical environment domain: home design (18.8\%).

\section{Parents group}

Fifteen items met the consensus criterion: no items from the physical environment domain, 8 from the attitudes and support domain, and 7 items from the social environment domain.

Six items reached the highest consensus level (100\%). Three belonged to the attitudes and support domain: attitudes of family at home, attitudes of teachers and health professionals, and support at school. The three others belonged to the social environment domain: government policies, cooperation between services, and programs and services in the community.

The item that reached the lowest consensus level belonged to the physical environment domain: natural environment $(26.3 \%)$.

\section{Consensus among groups}

At the end of the second round, 12 items reached global consensus, i.e., in all groups: attitudes of family at home (Q10); attitudes of teachers and HPs (Q12); attitudes of classmates and other age-mates (Q13); teachers and HPs listen to parent's opinion (Q19); support from family members at home (Q15); support at school (Q17); government policies (Q24); cooperation among social services (Q25); school type (Q26); parents' support group (Q28); parents' counseling services (Q29); and programs and services in the community (Q31).
Moreover, 3 items were common to HPs and teachers: neighborhood features (Q6); assistive devices (Q8); and daily life utilities (adapted clothing, toys, and books) (Q9). One was common to HPs and parents: respite services (Q30). Attitudes of wider family (Q11) was common to teachers and parents. House design (Q2), support from wider family (Q16), and support in the community (Q18) were, respectively, chosen only by HPs, teachers, and parents.

Relationship between rounds 1 and 2

According to Spearman's rho, there was a significant correlation between rounds 1 and 2 rankings in each of the 3 groups ( $r=0.95, p<0.001$ per each group).

Ranking of the items to prioritize for children with ID

Table 5 presents the top 10 prioritized items based on their total score. Five items were common to all 3 groups: attitudes of family members at home (Q10); attitude of teachers and HPs, (Q12); support from family members at home (Q15); support at school (from classmates, teachers) (Q17); and government policies (Q24).

Two items were selected by HPs and parents only: cooperation among social services (Q25); and programs and services in the community (Q31). Two items were common to HPs and teachers only: school type (mainstream, special) (Q26) and parents' counseling services (Q29). Two items were selected by teachers and parents only: attitudes of wider family (Q11) and attitudes of classmates and other age-mates (Q13). Parents' support group (Q28) was selected by HPs only, support in the community (Q18) by teachers only, and attitudes of people in public (Q14) by parents only. 
Content analysis

Participants' suggestions generated 16 new themes. Moreover 3 additional domains that do not fit in either of the environmental domains emerged: participation, family QOL or mental health, and family composition (Table 6).

\section{Discussion}

The Delphi technique was used to identify-by consensus among parents, health professionals, and teachersimportant environmental factors for CID's QOL.

The literature reveals that the number of rounds in a Delphi survey can vary from 2 to more successive rounds [35-37]. In the present study, we conducted 2 rounds. The Spearman's rho analysis revealed significance $(p<0.001)$, confirming the fact that items that were highly ranked in the first round according to consensus rates progressed towards much higher position in the second round. These results indicate that a third round was not indispensable.

At the end of the exercise, differences were observed within groups and between groups. As regards the differences within groups, items that did not meet consensus (determined by $75 \%$ consensus threshold) were sometimes selected when rank-ordered by the respondents. For example, in the parents group, item 14, which did not reach consensus, appears in the top 10 elements.

This divergence may be due first to the fact that respondents were primarily rating the environment by assigning values to individual items. This resulted in a wider selection of items, thus giving a broader view. However, ranking the 10 most important items gave the participants the opportunity to select the items that represent areas of perceived primary needs. The top 10 ranking was rendered easier because participants were by then aware of all items listed on the questionnaire. Thus, the top
10 gives more focused perspectives on which environmental factor is important and needed to foster CID's QOL. This does not mean that the other items, that reached the 75\% consensus threshold, are to be ignored. Rather they are to be addressed after the top 10 priorities are fulfilled. Another reason for this divergence might be that the ranking was performed by only a portion of the respondents (43 out of 59). However, this latter may be of little influence since the respondents (43) represented a large majority of second-round participants (73\%).

As regards the differences between groups, they might be secondary to the fact that ID is often associated with other disabilities (mental disorders, physical disorders, etc.) $[38,39]$. This explains that the environmental needs of children with intellectual disability vary according to the multiple possible associations between disorders. Apparently, HPs' and teachers' responses reflect a more distal and professional view encompassing the potential needs of this group of children as a whole. For instance, they selected physical elements (assistive devices) (Table 2) whereas the parents did not. HPs and teachers obviously consider the objective well-being in this case. With regard to parents, their view is more proximal and influenced by their perception of the child's emotional feelings. They privilege attitudes and support as well as social environment that influence subjective QOL (Table 3, 4).

This may suggest that the environmental needs of ID children are heterogeneous and can be appropriately understood when HPs, teachers, and parents collaborate to bring complementary ideas to improve the child's QOL. The opinions of each of the 3 groups (HPs, teachers, and parents) are equally important. It is necessary to consider all of them to obtain a thorough view of the child's needs.

In addition to the questionnaire items, participants suggested additional themes that reflected not only currently existing facts that might need improvement (e.g., medical services cooperation) but also innovative paths to be

Table 5 Ranking of items to prioritize for children with ID $(n=42)$

\begin{tabular}{|c|c|c|c|c|c|c|c|c|}
\hline \multicolumn{3}{|c|}{ HPs $(n=15)$} & \multicolumn{3}{|c|}{ Teachers $(n=12)$} & \multicolumn{3}{|c|}{ Parents $(n=15)$} \\
\hline Questions & Frequency & Total & Questions & Frequency & Total & Questions & Frequency & Total \\
\hline Q10 & 12 & 113 & Q10 & 11 & 102 & Q10 & 12 & 114 \\
\hline Q24 & 12 & 61 & Q15 & 9 & 68 & Q12 & 13 & 89 \\
\hline Q12 & 8 & 56 & Q24 & 8 & 61 & Q15 & 11 & 77 \\
\hline Q15 & 9 & 56 & Q12 & 8 & 57 & Q17 & 9 & 55 \\
\hline Q26 & 10 & 54 & Q13 & 8 & 54 & Q11 & 8 & 54 \\
\hline Q25 & 10 & 47 & Q17 & 11 & 51 & Q13 & 9 & 51 \\
\hline Q29 & 9 & 47 & Q11 & 5 & 36 & Q31 & 8 & 51 \\
\hline Q31 & 8 & 47 & Q26 & 5 & 29 & Q24 & 8 & 47 \\
\hline Q28 & 7 & 36 & Q18 & 6 & 25 & Q25 & 7 & 37 \\
\hline Q17 & 6 & 31 & Q29 & 5 & 24 & Q14 & 8 & 33 \\
\hline
\end{tabular}


Table 6 Themes generated by the participants

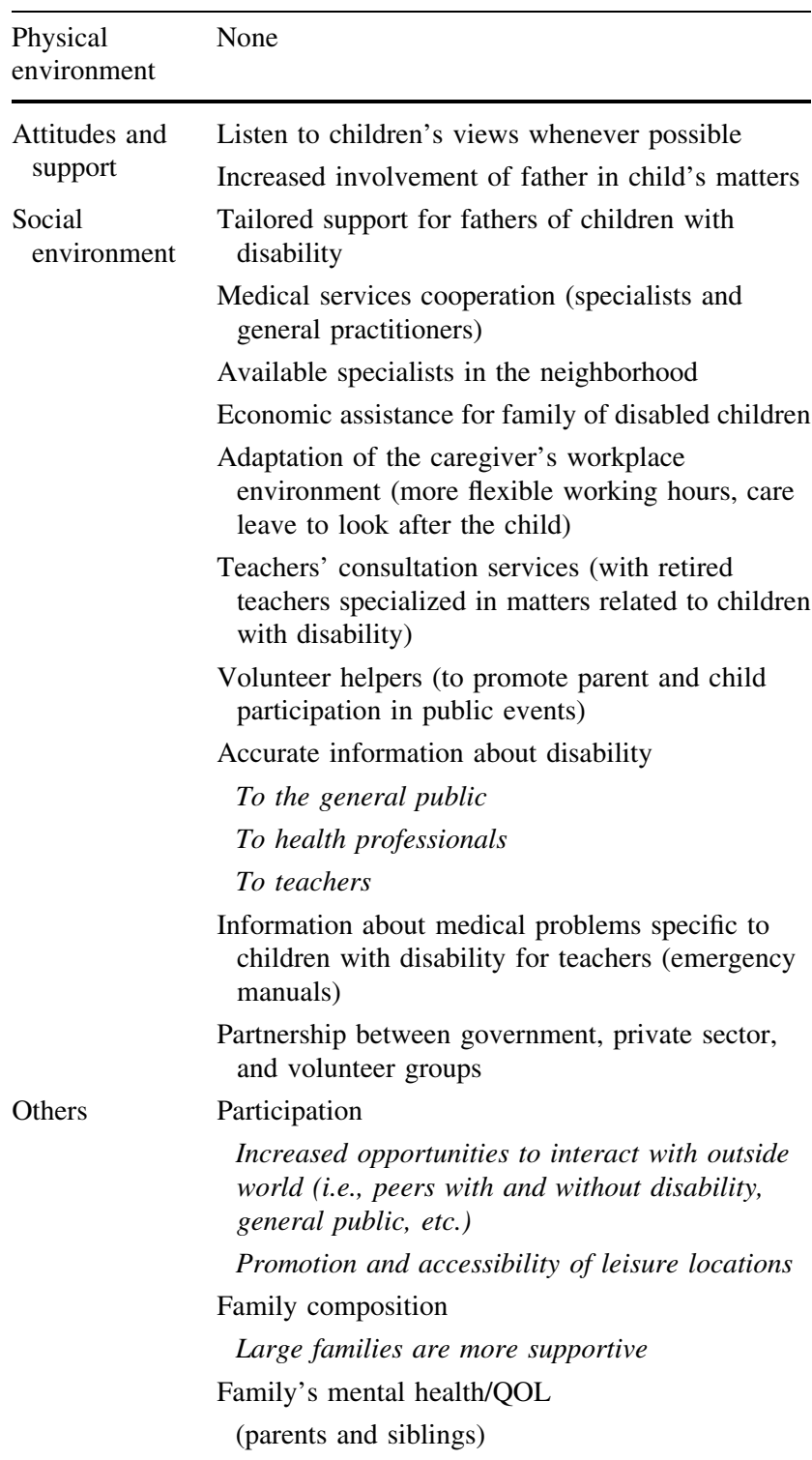

explored to improve children's QOL (e.g., consultation services conducted by retired teachers).

They also proposed other potentially important factors that could not be assigned to any of the environmental categories such as family composition, family QOL and mental health, and participation. This finding matches the relationship between QOL, participation, environment, and other personal factors (such as family composition) as suggested not only in the ICF [1] but also in the WHO definition of QOL [2].

Figure 1 illustrates the framework that we proposed for the well-being of children with intellectual disability. This figure results from the combination of themes generated by the content analysis of participants' comments and items that reached the $75 \%$ consensus threshold in the second round in at least one group.

To our knowledge, there is no previous study in which the environment of children with intellectual disability has been described in all its aspects (i.e., physical environment, attitudes and support, and social environment). However, the present results match findings from earlier studies which explored limited aspects of the environment of CID. Mactavish et al. [40] conducted focus groups with parents of CID about the meaning of their children's QOL. The following were designated as important by the participants: relationships with friends and family members, financial resources, and quality respite services. Brantly et al. [41] showed that the QOL of adolescents with intellectual disability is a function of school placement. Schormans et al. [42] proved that family environment and support to parents were important to support the child.

Globally, the participants in the present study stressed attitudes, support, policies, information, participation, and family. These elements are crucial to improve the QOL of disabled people in general and ID in particular. Policies encourage social inclusion of people with disabilities. However, people with disabilities often experience only physical integration without being really accepted in the society [43]. Information not only raises knowledge but also changes the attitudes towards and misconceptions about ID people in the general public but also in health professionals and teachers [20, 44-46]. Information is necessary to sustain policies in order to allow real inclusion of ID children in society and thus improve their participation and consequently their QOL [47]. It has been described that inclusion in society corresponds to higher participation $[47,48]$ and better QOL [49] in people with disabilities. Support of the child obviously impacts directly on his/her participation and QOL. Support also impacts on CID's family members by improving parents' mental health, family QOL, and quality of parenting [50, 51]. Better parent mental health, family QOL, and quality of parenting are also necessary conditions to improve the CID's QOL.

While the Delphi technique is a widely recognized method to analyze group opinion [52, 53], it also has some limitations. The legitimacy of the Delphi technique is based on appropriate selection of participants [54, 55]. They must validly represent the experts in the area under investigation [55]. In the current study, participants with different types and levels of expertise relevant to the life of children with intellectual disability were involved. However, all participants were from one prefecture of Japan. Future research should involve participants from different locations to gain a wider perspective.

In addition, observer (investigator) bias-due to improper data analysis-has also been described as a 
Fig. 1 Framework of the factors that influence QOL of children with intellectual disability

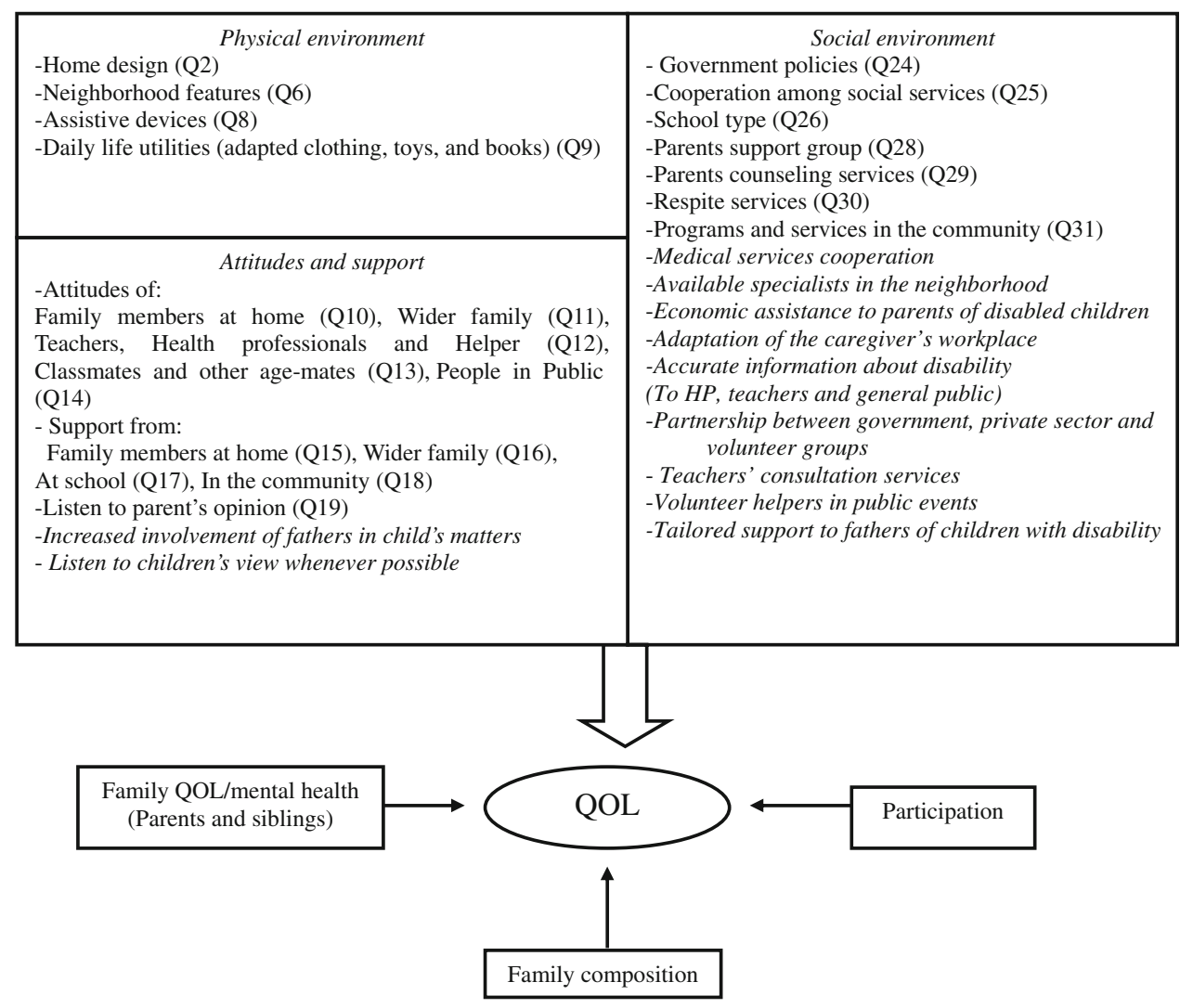

Italic: Elements generated by the panelists weakness of the Delphi exercise [54]. We do not think that this was the case in the present study since the investigator team was composed of members with previous experience in quantitative and qualitative research.

Also, questionnaire design has been highlighted as essential in Delphi exercise [54, 55]. In this study, the questionnaire was developed from literature review and reviewed before the survey by the investigators and also parent and teachers representatives to avoid any ambiguity.

Another limitation is that, in this Delphi survey, only parents, health professionals, and teachers were involved. Although the views of these 3 key elements in the life of a CID are of considerable importance, nothing has more value than the voice of the child himself. In future studies, the views of the child should be collected through adequate means of communication whenever possible.

Another aspect is that mainly mothers (21/22) were represented in the parents group. Fathers should also be included in the future. Their views and experience might yield further insight.

\section{Conclusion}

In this study, the Delphi technique was used to elicit the opinions of 3 different panels about the environmental needs of CID. At the end of the exercise, 18 items were selected. Based on these and additional items suggested by the participants, we built a framework of an environment conducive to the well-being of CIDs. This framework will be used as a basis for the development of an instrument to assess the living environment of CIDs.

Acknowledgments The authors would like to thank the parents, teachers, and health professionals for their participation to this study.

Conflict of interest statement There are no conflicts of interest including any financial, personal or other relationships with persons or organizations for any author related to the work described in this article.

\section{References}

1. World Health Organization. International classification of functioning, disability and health: ICF. Geneva: World Health Organization; 2001.

2. WHOQOL Group. Measuring quality of life: the development of the World Health Organization Quality of Life Instrument (WHOQOL). Geneva: World Health Organization; 1993.

3. McGrath B, Brennan MA, Dolan P, Barnett R. Adolescent wellbeing and supporting contexts: a comparison of adolescents in Ireland and Florida. J Community Appl Soc Psychol. 2009; 19(4):299-320. 
4. Sugiyama T, Ward Thompson C, Alves S. Associations between neighborhood open space attributes and quality of life for older people in Britain. Environ Behav. 2009;41(1):3-21.

5. Richards JS, Bombardier CH, Tate D, Dijkers M, Gordon W, Shewchuk R, et al. Access to the environment and life satisfaction after spinal cord injury. Arch Phys Med Rehabil. 1999;80(11):1501-6.

6. Keysor JJ, Jette AM, Coster W, Bettger JP, Haley SM. Association of environmental factors with levels of home and community participation in an adult rehabilitation cohort. Arch Phys Med Rehabil. 2006;87(12):1566-75.

7. Van Blarikom W, Tan IY, Aldenkamp AP, van Gennep ATG. Epilepsy, intellectual disability, and living environment: a critical review. Epilepsy Behav. 2006;9(1):14-8.

8. Hammel KW. Perspectives on disability \& rehabilitation. New York: Churchill Livingstone; 2006.

9. Chan SC, Chan AP. User satisfaction, community participation and quality of life among Chinese wheelchair users with spinal cord injury: a preliminary study. Occup Ther Int. 2007;14(3):123-43.

10. Whiteneck G, Meade MA, Dijkers M, Tate DG, Bushnik T, Forchheimer MB. Environmental factors and their role in participation and life satisfaction after spinal cord injury. Arch Phys Med Rehabil. 2004;85(11):1793-803.

11. Colver A. Study protocol: SPARCLE - a multi-centre European study of the relationship of environment to participation and quality of life in children with cerebral palsy. BMC Public Health. 2006;25(6):105.

12. Keysor JJ. How does the environment influence disability? Examining the evidence. In: Field MJ, Jette AM, Martin L, editors. Workshop on disability in America a new look-summary and background paper. Washington DC: The National Academies Press; 2006. pp. 88-100.

13. Law M, Petrenchik T, King G, Hurley P. Perceived environmental barriers to recreational, community, and school participation for children and youth with physical disabilities. Arch Phys Med Rehabil. 2007;88(12):1636-42.

14. Almqvist L, Granlund M. Participation in school environment of children and youth with disabilities: a person-oriented approach. Scand J Psychol. 2005;46(3):305-14.

15. Mihaylov SI, Jarvis SN, Colver A, Beresford B. Identification and description of environmental factors that influence participation of children with cerebral palsy. Dev Med Child Neurol. 2004;46(5):299-304.

16. World Health Organization. The World Health Organization report 2001-mental health: new understanding new hope. Geneva: World Health Organisation; 2001.

17. Cabinet Office Japan [homepage on the Internet]. Tokyo: Cabinet Office, Government of Japan; c2006. [Cited 2009 Feb 4]. Annual report on government measures for persons with disabilities. Available from:http://www8.cao.go.jp/shougai/english/annual report/2003/6-1.html.

18. Tachibana T, Watanabe K. Attitudes of Japanese adults toward persons with intellectual disability: relationship between attitudes and demographic variables. Educ Train Dev Disabil 2004; 39(2):109-26.

19. Horner-Johnson W, Keys C, Henry D, Yamaki K, Oi F, Watanabe $\mathrm{K}$, et al. Attitudes of Japanese students toward people with intellectual disability. J Intellect Disabil Res. 2002;46(5):365-78.

20. Horiguchi T, Inagaki M, Kaga M. Japanese physicians' attitude for utilization of social support services for persons with intellectual disabilities. No To Hattatsu. 2004;36(5):365-71. (article in Japanese).

21. Adler M, Ziglio E. Gazing into the oracle. Philadelphia: Jessica Kingsley; 1996.

22. Oertel BJ. Identifying the essential characteristics of curricular learning communities in higher education: a Delphi study.
Winona: Winona State University; 2001. [Cited 2009 August 20]. Available from: http://www.winona.edu/advising/LC.

23. Gordon TJ, Helmer O. "Report on a long range forecasting study," Rand paper P-298. Santa Monica: Rand Corporation; 1964. [Cited 2009 February 4]. Available from: http://www.rand. org/pubs/papers/P2982/.

24. Morita T, Bito S, Kurihara Y, Uchitomi Y. Development of a clinical guideline for palliative sedation therapy using the delphi method. J Palliat Med. 2005;8(4):716-29.

25. Chin J, Sato PA, Mann JM. Projections of HIV infections and AIDS cases to the year 2000. Bull World Health Organ. 1990; 68(1):1-11.

26. Wilkinson G, Williams P. Priorities for research on mental health in primary care settings. Psychol Med. 1985;15(3):507-14.

27. Longhurst RW, Call DL. Scientific consensus, nutrition programs and economic planning. Am J Clin Nutr. 1975;28(10): $1177-82$.

28. Harrison-Felix C. The Craig Hospital inventory of environmental factors. The Center for Outcome Measurement in Brain Injury; 2001. [Cited 2009 February 4] Available from: http://www.tbims. org/combi/chief/.

29. Boschen K, Noreau L, Fougeyrollas P. A new instrument to measure the quality of the environment for persons with physical disabilities. Arch Phys Med Rehabil. 1998;79:1331.

30. Keysor JJ, Jette AM, Haley SM. Development of the home and community environment (HACE) instrument. J Rehabil Med. 2005;37(1):37-44.

31. Sinicrope PS, Patten CA, Bonnema SM, Almquist JR, Smith CM, Beebe TJ, et al. Healthy women's motivators and barriers to participation in a breast cancer cohort study: a qualitative study. Ann Epidemiol. 2009;19(7):484-93.

32. Yoshida S, Otani H, Hirai K, Ogata A, Mera A, Okada S, et al. A qualitative study of decision-making by breast cancer patients about telling their children about their illness. Support Care Cancer. 2009. doi10.1007/s00520-009-0682-7.

33. Dashiff CJ. Parents' perceptions of diabetes in adolescent daughters and its impact on the family. J Pediatr Nurs. 1993; $8(6): 361-9$.

34. University of Texas at Austin. Instructional Assessment Resources. Glossary. Available from: http://www.utexas.edu/academic/ diia/assessment/iar/glossary.php. Accessed August 18, 2009.

35. Kobayashi K, Ueno F, Bito S, Iwao Y, Fukushima T, Hiwatashi $\mathrm{N}$, et al. Development of consensus statements for the diagnosis and management of intestinal Behcet's disease using a modified Delphi approach. J Gastroenterol. 2007;42(9):737-45.

36. Jackson MM, Lynch P. Development of a numeric health care worker risk-assessment scale to evaluate potential for bloodborne pathogen exposures. Am J Infect Control. 1995;23(1):1321.

37. Shortridge L, Doswell W, Evans ME, Levin RF, Millor GK, Carter E. 1988 Delphi survey of nursing research priorities for New York state. J NY State Nurses Assoc. 1989;20(3):15-9.

38. Jansen DEMC, Krol B, Groothoff JW, Post D. People with intellectual disability and their health problems: a review of comparative studies. J Intellect Disabil Res. 2004;48(2):93-102.

39. Porter RS, Kaplan JL, Homeier BP, Beers MH. Merck manuals: online medical library. Whitehouse station, NJ: Merck Research Laboratories; 2006 [Cited 2009 August 5]. Available from: http://www.merck.com/mmhe/index.html.

40. Mactavish JB, MacKay KJ, Iwasaki Y, Betteridge D. Family caregivers of individuals with intellectual disability: perspectives on life quality and the role of vacations. J Leisure Res. 2007;39(1):127-55.

41. Brantley A, Huebner ES, Nagle RJ. Multidimensional life satisfaction reports of adolescents with mild mental disabilities. Ment Retard. 2002;40(4):321-9. 
42. Schormans AF, Coniega M, Renwick R. Placement stability: enhancing quality of life for children with developmental disabilities. Fam Soc. 2006;87(4):521-8.

43. Nakayama K. Japanese laws and policies concerning persons with disabilities: to develop a normalized society through recreation. Educ Res Pol Pract. 2004;3(1):3-16.

44. Johnston C, Dixon R. Nursing student's attitudes towards people with disabilities can they be changed? [Cited 2009 February 4]. Available from http://www.aare.edu.au/98pap/ joh98196.htm.

45. Nursey AD, Rohde JR, Farmer RDT. A study of doctors' and parents' attitudes to people with mental handicaps. J Ment Defic Res. 1990;34(2):143-55.

46. Phtiaka H. Children with special needs in the ordinary classroom: teachers' and peers' views; 2005 [Cited 2009 February 4]. Available from http://www.isec2005.org/isec/abstracts/papers_ p/phtiaka_h.shtml.

47. United Nations. The United Nations standard rules on the equalization of opportunities for persons with disabilities. G.A. res. 48/96, 48 U.N. GAOR Supp. [No. 49], U.N. Doc. A/48/49. New York: United Nations; 1993.
48. Mitchell D. Special educational needs and inclusive education: inclusive education. New York: Routledge; 2004.

49. Brown I. Quality of life and disability: an approach for community practitioners. London: Jessica Kingsley; 2009.

50. Shin JY, McDonaugh RG. Types, availability, and perception of social support among parents of young children with cognitive delays in Vietnam. Int J Rehabil Res. 2008;31(2):131-9.

51. Armstrong MI, Birnie-Lefcovitch S, Ungar MT. Pathways between social support, family well being, quality of parenting, and child resilience: what we know. J Child Fam Stud. 2005; 14(2):269-81.

52. Hasson F, Keeney S, McKenna H. Research guidelines for the Delphi survey technique. J Adv Nurs. 2000;32(4):1008-15.

53. Jones J, Hunter D. Consensus methods for medical and health services research. Br Med J. 1995;311(7001):376-80.

54. Linstone $\mathrm{H}$, Turoff $\mathrm{M}$. The Delphi method: techniques and applications; 1975. [Cited 2009 August 19].Available from: http://www.is.njit.edu/pubs/delphibook.

55. Shields TJ, Silcock GWH, Donegan HA, Bell YA. Methodological problems associated with the use of the Delphi technique. Fire Technol. 1987;23(3):175-85. 